IP Periodica Polytechnica

Transportation Engineering

45(4), pp. 211-217, 2017

https://doi.org/10.3311/PPtr.9775

Creative Commons Attribution (1)

RESEARCH ARTICLE

\section{Using Video to Validate Vehicle Speed Uncertainty in Vertical Side Collisions}

\author{
Jianjun Yang ${ }^{1,2^{*}}$, Dawei Dong ${ }^{1}$, Pingfei $\mathrm{Li}^{2,3}$, Tao Liang ${ }^{4}$, \\ Zhiyong Zhang ${ }^{5}$
}

Received 20 July 2016; accepted 08 December 2016

\begin{abstract}
Vehicle speed access is an important part of road traffic accidents. Many factors affect the speed of the vehicle in vertical side collisions. Uncertainty in speed calculations related to vehicle collision was researched. The main parameters which have a greater impact on the speed of calculation results were discussed. And speed calculation methods based on uncertainty factors have been analyzed. By use of the vehicle vertical side collisions case, the speed of uncertainty has been carried out. Combined with accident surveillance video, the video picture computed speed and uncertainty factors obtained speed were compared. The results showed that selected road adhesion coefficient, vehicle weight and other parameters as the uncertainty factors, the use of uncertainty obtained speed with high reliability of forensic, which can be used in accident reconstruction.
\end{abstract}

\section{Keywords}

traffic accident, vehicle speed, uncertainty, uncertainty factor, video

\footnotetext{
${ }^{1}$ School of Mechanical Engineering, Southwest Jiaotong University, Chengdu, China

${ }^{2}$ School of Automobile and Transportation, Xihua University, Chengdu, China

${ }^{3}$ Sichuan Xihua Vehicle Forensic Institute, Chengdu, China

${ }^{4}$ Collaborative Innovation Center of Automotive Key Components, Chengdu, China

${ }^{5}$ Institute of Forensic Science, Ministry of Justice, PRC, Shanghai, China

${ }^{*}$ Corresponding author, e-mail: yangji@mail.xhu.edu.cn
}

\section{Introduction}

During 2008, road traffic injuries ranked fourth among the leading causes of death in the word. A road traffic accident involves high socioeconomic costs and human suffering in terms of injuries, abnormal deaths, loss of productivity, etc. In China, the motor vehicle population is growing at a rate faster than the economic and road growth. Therefore, the high incidence of traffic accidents has become the main features of China traffic accident (Cao et al., 2014). Vehicle side collisions constitute the largest category of road traffic accidents in China. In 2013, there were 198,394 road traffic accidents, 213,724 injured in traffic crashes, and 58,539 people killed. According to the Ministry of Public Security Traffic Management Bureau of China, vehicle side collisions accounted for $40.36 \%$ of all traffic, and $29.02 \%$ of all fatalities.

Speeding is one of the most common driving behaviours despite being one of the biggest contributors to road fatalities and injuries (Adrian and Stephen, 2015; Cheng and Pei, 2008). Many studies have been conducted to examine the vehicle speed involved in crashes and determine the contributory factors (Qu et al., 2015). And speed research on traffic accident is one of the most important issues in terms of traffic safety management. It has been extensively studied the relationship between accidents and the speed in the world. For instance, several studies found that more than 20 percent of drivers admitted to speeding in the accident (Peer, 2011; Tarko, 2009). Taylor et al. (2000; 2002) examined the relationship between vehicle speed and crashes, which found 1 mile/h change in average speed was associated with a 5 percent increase in crashes with most road types.

Cheng and Pei (2008) and Çavdar et al. (2008) analyzed the characteristics of traffic accidents in China and Turkey, the two countries are very similar in that speeding was a major cause of traffic accidents. In China, the traffic police division of responsibilities when the side collision accident occurred, one of the most important reference basis is the vehicle speed at the time of the accident, to determine whether the parties it is illegal to speeding (Cui et al., 2014; Shen et al., 2009). So speed analysis of accident reconstruction is significant and essential in China. 
Vehicle speed in traffic accidents were identified, which mainly obtained by theoretical calculations, empirical estimation, computer software modeling analysis, experimental test, instrumental measurement, monitoring data analysis, human bodies' characteristic injuries analysis, and so on (Cao et al., 2014; Zhao et al., 2015). In most cases, the speed of access is not directly, but through site inspection, combined with vehicle deformation and other technical analysis (Çelik and Senger, 2014). In general, the conclusion that the vehicle before the collision with the vehicle speed is given a reasonable range. Because accidents irreversible, for some parameters in the accident can't be accurately obtained, the speed of the results will create uncertainty (Shen et al., 2009; Ward et al., 2014). Therefore, uncertainty analysis is introduced to calculate the vehicle speed of the accident reconstruction. By selecting a greater impact on several parameters uncertainty as uncertainty factor, according to the range of uncertainty factors to estimate the range of the vehicle speed, the reproduction of the accident analysis is possible (Shen et al., 2009; Wojciech and Jan, 2006).

Wojciech and Jan (2006) applied Monte Carlo simulation models to analyze the vehicle velocities and collision location. Also, Wojciech and Jan (2007) researched the collision speeds using reconstruction and simulation methods, and proved the necessity of including the problem of uncertainty in calculation of vehicle speed. In this paper, the speed identification occurs between the vertical sides collision accident was analysis, and a case analysis was performed based on the vehicle speed uncertainty theory. By using video picture methods, uncertainty theory speed is compared. The results showed that by introducing a greater impact on the calculation results of parameters and reference to uncertainty, the speed calculation can be close to the true value.

\section{Accident reconstruction basic theory}

A schematic vertical side collision accident occurred as shown in Fig. 1. By the momentum conservation theorem, in the collision occurred during the vertical sides, the total momentum remains unchanged before and after the collision. The following Eq. (1) is obtained.

$$
\left\{\begin{array}{l}
m_{1} v_{10}=m_{1} v_{1} \cos \alpha+m_{2} v_{2} \sin \beta \\
m_{2} v_{20}=m_{1} v_{1} \sin \alpha+m_{2} v_{2} \cos \beta
\end{array}\right.
$$

In Eq. (1), where

$m_{1}, m_{2}$--- the total weight of the vehicle $A$ and $B$, with the unit of $\mathrm{kg}$;

$v_{10}, v_{20}$--- the speed of the vehicle $A$ and $B$ before the collision, with the unit of $\mathrm{m} / \mathrm{s}$;

$v_{1}, v_{2}$--- the speed of the vehicle $A$ and $B$ after the collision, with the unit of $\mathrm{m} / \mathrm{s}$;

$\alpha, \beta$--- the deflection angle of the vehicle $A$ and $B$ from the original direction after the collision, with the unit of ${ }^{\circ}$.

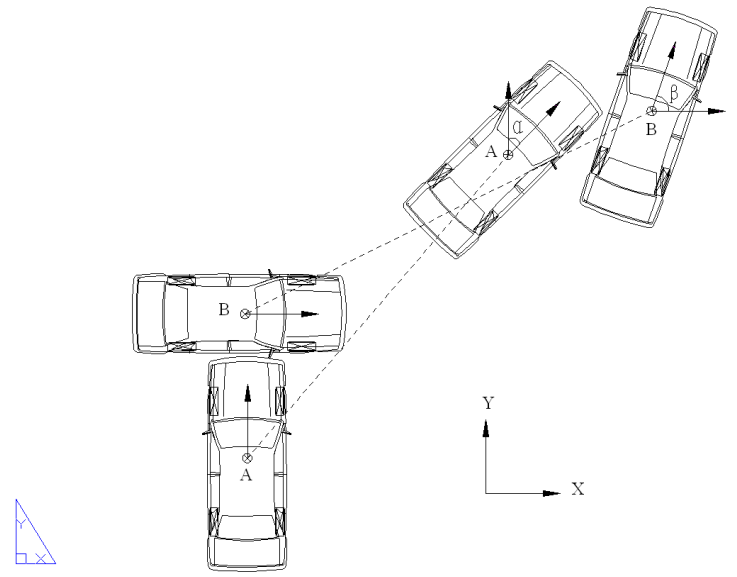

Fig. 1 Schematic diagram of vertical side collision

The speed of the vehicle $A$ and $B$ before the collision can be obtained from Eqs. (1), as shown in Eq. (2).

$$
\left\{\begin{array}{l}
v_{10}=v_{1} \cos \alpha+\frac{m_{2}}{m_{1}} v_{2} \sin \beta \\
v_{20}=\frac{m_{1}}{m_{2}} v_{1} \sin \alpha+v_{2} \cos \beta
\end{array}\right.
$$

As the vehicle collision time is very short, according to the law of conservation of energy, the kinetic energy of the vehicle after the collision is considered completely converted into friction energy with ground. In the case of ignoring the brake coordination time, according to the movement distance of the vehicle after the collision, the vehicle rear collision instantaneous velocity can be calculated, as shown in Eq. (3).

$$
\left\{\begin{array}{l}
v_{1}=\sqrt{2 g \phi_{1} s_{1}} \\
v_{2}=\sqrt{2 g \phi_{2} s_{2}}
\end{array}\right.
$$

In Eq. (3)

$g$--- the acceleration of gravity, $9.8 \mathrm{~m} / \mathrm{s}^{2}$;

$\phi_{1}, \phi_{2}$--- the friction coefficients of the vehicle $A$ and $B$ with road surface;

$s_{1}, s_{2}$---the movement length of the vehicle $A$ and $B$ after the collision, with the unit of $m$.

Equation (3) is substituted into Eq. (2), the speed of the vehicle before the collision can be obtained with the vehicle in the form of a vertical side collision, as shown in Eq. (4).

$$
\left\{\begin{array}{l}
v_{10}=\sqrt{2 g \phi_{1} s_{1}} \cos \alpha+\frac{m_{2}}{m_{1}} \sqrt{2 g \phi_{2} s_{2}} \sin \beta \\
v_{20}=\frac{m_{1}}{m_{2}} \sqrt{2 g \phi_{1} s_{1}} \sin \alpha+\sqrt{2 g \phi_{2} s_{2}} \cos \beta
\end{array}\right.
$$

\section{Uncertainty of vertical side collision}

Measurement uncertainty is used to describe the level of uncertainty, which is used to describe the real value is measured in a range of an estimate (Bartlett et al., 2002; Fonda, 2004). In the analysis of road traffic accidents, two 
types of calculation result uncertainty can be distinguished: one is modelling uncertainty, the other is uncertainty in calculation results (Wojciech and Jan, 2006). Evaluation of the uncertainty, a specific process including modeling, standard uncertainty assessment, combined standard uncertainty calculation, the expanded uncertainty calculations, and finally, the uncertainty of the report is generated.

In the standard uncertainty assessment, Class $A$ and $B$ should be distinguished. Class $A$ is usually assessed for statistical analysis of the observed column. Class $B$ is the other remaining method of assessment. Obviously, in the evaluation of vehicle speed in traffic accidents uncertainty, Class $B$ assessment methods should be used.

\subsection{Uncertainty theory}

Suppose, in the actual establishment of the mathematical model, parameters $Y$ obtained by calculation, and $Y$ decided by several independent inputs. These inputs have uncertainty, which is as follows.

$$
Y=F\left(X_{1}, X_{2} \ldots X_{n}\right)
$$

Therefore, the optimal value of $y$ may be obtained by computing the optimal values of the parameters $x_{i}$, that is

$$
y=f\left(x_{1}, x_{2} \ldots x_{n}\right)
$$

That is, the uncertainty of $y$ is determined by the uncertainty of $x_{i} . u_{x i}$ is defined as $x_{i}$ 's standard uncertainty. $u_{x i}$ acquisition, is to change the radius $a_{i}$ of $x_{i}$ obtained by dividing the coverage factor $k_{i}$, that is

$$
u_{x i}=a_{i} / k_{i}
$$

On normal distribution, corresponding to 0.95 confidence level, the coverage factor is 2 (Yuan et al., 2001). And then the relative standard uncertainty component is calculated.

$$
u_{x i}^{\prime}=u_{x i} /\left|x_{i}\right|
$$

The relative change in $y$ and $u_{x i}$ are called corresponding uncertainty propagation coefficient by $\delta_{i}=\frac{\partial y}{\partial x_{i}}$. Thus, the relative uncertainty of $y$ can be described as

$$
u_{y i}^{\prime}=\left|\delta_{i}\right| u_{x i}^{\prime} \frac{x_{i}}{y}
$$

The formula (9) shows the relative uncertainty of function due to the relative amount of uncertainty introduced by a certain input calculation results.

In the joint action of all model inputs, the relative combined standard uncertainty function $y$ would be described by the following formula

$$
u_{y}^{\prime}=\sqrt{\sum_{i=q}^{n} u_{y i}^{\prime 2}}=\sqrt{\sum_{i=1}^{n}\left(\delta_{i} u_{x i}^{\prime} \frac{x_{i}}{y}\right)^{2}}
$$

The relative expanded uncertainty is the relative combined standard uncertainty multiplied by a coverage factor $k$, that is

$$
U^{\prime}=k u_{y}^{\prime}
$$

Thus, the ranges of $Y$ can be described as follows

$$
Y=y \pm y U^{\prime}=y\left(1 \pm U^{\prime}\right)
$$

\subsection{Uncertainty Factor and Slight uncertainty}

As the automotive collision speed is affected by many factors, the influence of various factors are not the same. In rder to control the influence of selected parameter errors on calculation results of vehicle collision models based on momentum theorem, Zhang et al. (2012) proposed a sensitivity analysis method of selected parameters by applying matrix theory on the base of influence mechanism analysis. The results show that when the relative calculation error is less than or equal to $5 \%$, the maximum error range of selected parameters is $\pm 16.12 \%$ and the reasonable range of selected parameters is determined accordingly. Thus, when in actual operation, slight uncertainty can be defined (Helton and Davis, 2003; Yuan et al., 2001). Compared with all the overall impact of uncertainty, the uncertainty of a negligible impact is deemed to be slight uncertainty. In other words, if the actual work that the difference between the impacts of omitted after the original impact is less than $1 / 10$ of the original, the uncertainty can be regarded as slight uncertainty, which could be omitted.

As can be seen from the Eq. (10), for each input uncertainty factor introduced, they are superimposed in the form of square. Therefore, when the value of an argument in which the most uncertainty, uncertainty in the parameter is significantly larger than the other parameters, this parameter uncertainty will dominate (Yuan et al., 2001). This parameter is the greatest impact on the results of the uncertainty, and the uncertainty of other parameters can be ignored.

By using uncertainty propagation and synthesis theory, it can make the algorithm accident reconstruction get some simplified. For vehicle traffic accidents, the most significant parameter is selected as an uncertainty factor to calculate vehicle speed.

\subsection{Uncertainty in the vehicle speed before collision}

Vehicle collision speed is affected by many factors, such as vehicle weight, road adhesion coefficient, braking distance, the amount of deformation and the like. Shen et al. (2009) discussed the main factors of speed uncertainty, a fuzzy rulebased evidential reasoning algorithm was employed in preimpact velocity calculation. Zhang et al. (2012) analyzed the sensitivity on the selected parameters in typical vehicle collision models. The impact of various factors on the size of the vehicle speed is not the same sensitivity. Difference of simplified and original impact is less than $1 / 10$ of the original impact, the uncertainty introduced by the factors may 
be considered as slight uncertainty. Slight uncertainty in the calculation can be ignored.

According to the theory of uncertainty from the Eq. (2) shows, the impact of the vertical sides collision speed related parameters is $m_{1}, m_{2}, \phi_{1}, \phi_{2}, \alpha, \beta, s_{1}, s_{2}$. It can be written as the following equation.

$$
\left\{\begin{array}{l}
v_{10}=f_{1}\left(m_{1}, m_{2}, \alpha, \beta, v_{1}\left(\phi_{1}, s_{1}\right), v_{2}\left(\phi_{2}, s_{2}\right)\right) \\
v_{20}=f_{2}\left(m_{1}, m_{2}, \alpha, \beta, v_{1}\left(\phi_{1}, s_{1}\right), v_{2}\left(\phi_{2}, s_{2}\right)\right)
\end{array}\right.
$$

Since $\alpha, \beta, s_{1}, s_{2}$ are at the accident site measurements obtained by measuring instrument. As long as the measuring tools and methods under right conditions, the true value is to be obtained. The range is small relative to other errors. So, the measurement error introduced by the scene geometry can be regarded as slight uncertainty. Therefore, the equation can be further simplified as follows.

$$
\left\{\begin{array}{l}
v_{10}=f_{1}^{*}\left(m_{1}, m_{2}, v_{1}\left(\phi_{1}\right), v_{2}\left(\phi_{2}\right)\right) \\
v_{20}=f_{2}^{*}\left(m_{1}, m_{2}, v_{1}\left(\phi_{1}\right), v_{2}\left(\phi_{2}\right)\right)
\end{array}\right.
$$

Among them, $\phi_{1}, \phi_{2}$ introduced the second-order uncertainty. According to the theory of uncertainty, Eq. (2) is subjected to partial differentiation. Four uncertainty propagation coefficients were obtained with vehicle $A$ before the collision.

$$
\left\{\begin{array}{l}
\delta_{1}=\frac{\partial v_{10}}{\partial m_{1}}=-\frac{m_{2} v_{2}}{m_{1}^{2}} \sin \beta \\
\delta_{2}=\frac{\partial v_{10}}{\partial m_{2}}=\frac{v_{2}}{m_{1}} \sin \beta \\
\delta_{3}=\frac{\partial v_{10}}{\partial v_{1}}=\cos \alpha \\
\delta_{4}=\frac{\partial v_{10}}{\partial v_{2}}=\frac{m_{2}}{m_{1}} \sin \beta
\end{array}\right.
$$

Further, the relative combined standard uncertainty of $v_{10}$ can be obtained.

$$
\begin{aligned}
u_{v_{10}}^{\prime} & =\sqrt{\sum_{i=1}^{4} u_{v_{10 i}}^{\prime}}=\sqrt{\left(\delta_{1} \mu_{x 1}^{\prime} \frac{m_{1}}{v_{10}}\right)^{2}+\left(\delta_{2} \mu_{x 2}^{\prime} \frac{m_{2}}{v_{10}}\right)^{2}} \\
& +\left(\delta_{3} \mu_{x 3}^{\prime} \frac{v_{1}}{v_{10}}\right)^{2}+\left(\delta_{4} \mu_{x 4}^{\prime} \frac{v_{2}}{v_{10}}\right)^{2}
\end{aligned}
$$

Similarly, the relative combined standard uncertainty of vehicle $B$ can be obtained. It is describes as follows:

$$
\begin{aligned}
u_{V_{20}}^{\prime} & =\sqrt{\sum_{i=1}^{4} u_{v_{20 i}}^{\prime}}=\sqrt{\left(\delta_{1}^{\prime} \mu_{x 1}^{\prime} \frac{m_{1}}{v_{20}}\right)^{2}+\left(\delta_{2}^{\prime} \mu_{x 2}^{\prime} \frac{m_{2}}{v_{20}}\right)^{2}} \\
& +\left(\delta_{3}^{\prime} \mu_{x 3}^{\prime} \frac{v_{1}}{v_{20}}\right)^{2}+\left(\delta_{4}^{\prime} \mu_{x 4}^{\prime} \frac{v_{2}}{v_{20}}\right)^{2}
\end{aligned}
$$

\section{Case analysis}

In order to verify the above model, a vertical side collision accident was used to make verification. The case: On the morning of July 9, 2015, it was sprinkling, and a vehicle collided with another vehicle by vertical side collision near a crossing in the downtown of Chengdu, leading to the death of the occupants and vehicle damage. As illustrated in Fig. 2, it happened on a wet asphalt road.

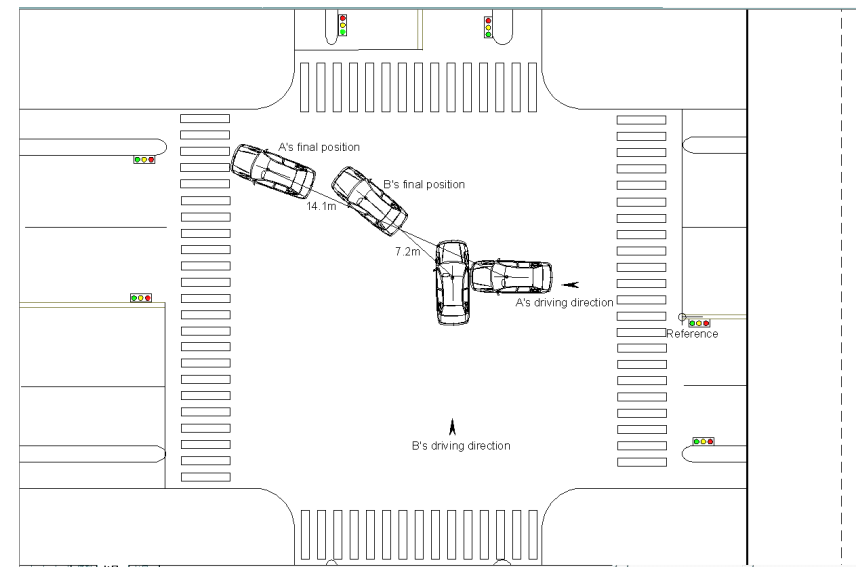

Fig. 2 Schematic diagram of accident scene

As can be seen from the Fig. 3 and Fig. 4, vehicle $A$ 's front and vehicle $B$ 's side were severely damaged, so the accident is a typical vertical side collision. After on-site investigation, all the tires are relatively new, and the accident belongs to the new asphalt road paving. Therefore, the value of the parameters can be selected according to the national standard recommendation and consider bringing in uncertainty.

Vehicle $A$ collision at a distance of movement by $14.1 \mathrm{~m}$, vehicle B's corresponding to $7.2 \mathrm{~m}$, angle changes in amounts of $22^{\circ}$ and $65^{\circ}$. Participants related parameters, the parameter values of the accident scene and vehicle shown in Table 1.

Table 1 Scope of input parameters

\begin{tabular}{llll}
\hline $\begin{array}{l}\text { Vehicle } A \text { 's } \\
\text { parameters }\end{array}$ & $\begin{array}{l}\text { Best value and } \\
\text { the range }\end{array}$ & $\begin{array}{l}\text { Vehicle } B \text { 's } \\
\text { parameters }\end{array}$ & $\begin{array}{l}\text { Best value and } \\
\text { the range }\end{array}$ \\
\hline$\phi_{1}$ & $0.55 \pm 0.05$ & $\phi_{2}$ & $0.55 \pm 0.05$ \\
$s_{1} / m$ & 14.1 & $s 2 / m$ & 7.2 \\
$v_{1} / m \cdot s^{-1}$ & $12.33 \pm 0.56$ & $v_{2} / m \cdot s^{-1}$ & $8.81 \pm 0.40$ \\
$m_{1} / k g$ & $1700 \pm 50$ & $m_{2} / k g$ & $1400 \pm 50$ \\
$\alpha /\left(^{\circ}\right)$ & 22 & $\beta /\left(^{\circ}\right)$ & 65 \\
\hline
\end{tabular}

On this basis, standard uncertainty, the relative standard uncertainty, uncertainty propagation coefficient, relative standard uncertainty components of vehicle $A$ can be calculate.

Finally, the relative combined standard uncertainty and expanded uncertainty are obtained, the data shown in Table 2.

Using the same method, corresponding data of vehicle $B$ can be obtained, the data shown in Table 3. 


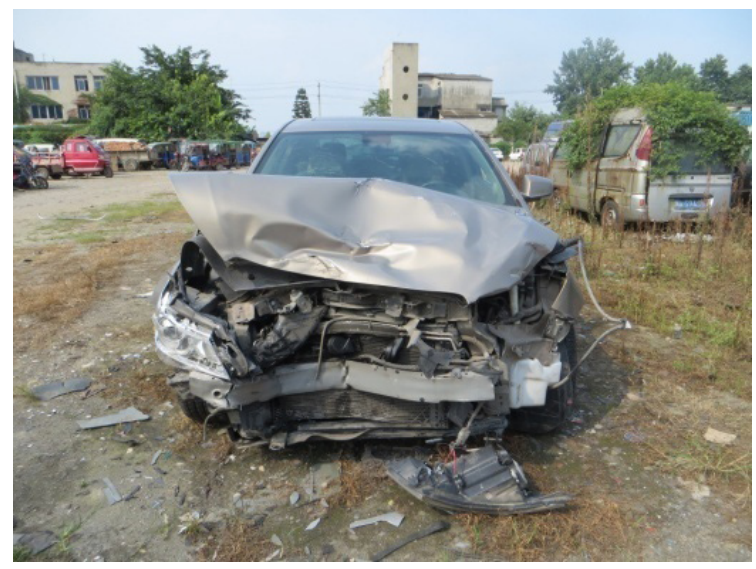

Fig. 3 Vehicle $A$ 's damaged condition

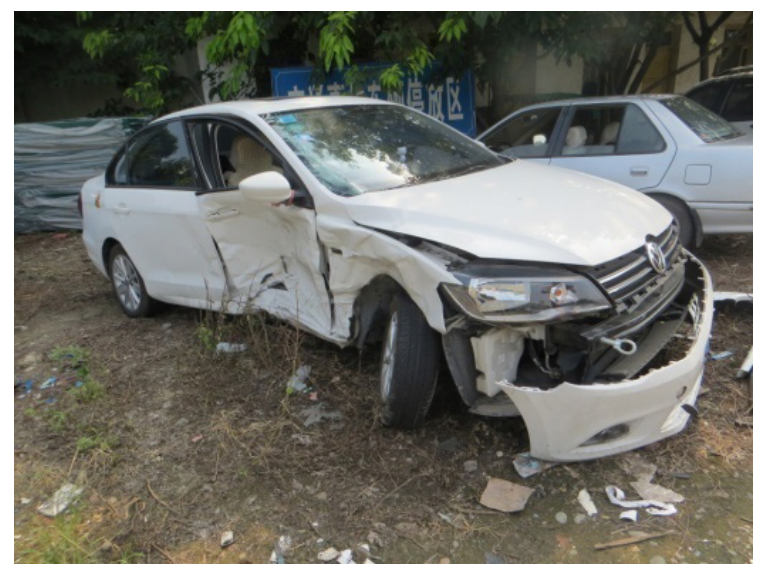

Fig. 4 Vehicle $B$ 's damaged condition

Table 2 Uncertainties of speed pre-crash of vehicle $A$

\begin{tabular}{|c|c|c|c|c|c|c|c|c|}
\hline $\begin{array}{l}\text { Input } \\
\text { parameters } \\
x_{i}\end{array}$ & $\begin{array}{l}\text { Changes } \\
\text { radius } \\
a_{i}\end{array}$ & $\begin{array}{l}\text { Contains } \\
\text { factor } \\
k\end{array}$ & $\begin{array}{l}\text { Standard } \\
\text { Uncertainty } \\
u_{\mathrm{xi}}\end{array}$ & $\begin{array}{l}\text { Relative standard } \\
\text { uncertainty } \\
u_{x i}^{\prime}\end{array}$ & $\begin{array}{l}\text { Uncertainty } \\
\text { propagation } \\
\text { coefficient } \\
\delta_{i}\end{array}$ & $\begin{array}{l}\text { Relative standard } \\
\text { uncertainty } \\
\text { component } \\
u_{v_{\text {Iox }}^{\prime}}^{\prime}\end{array}$ & $\begin{array}{l}\text { Relative combined } \\
\text { standard } \\
\text { uncertainty } \\
u_{v 10}^{\prime}\end{array}$ & $\begin{array}{l}\text { Expanded } \\
\text { uncertainty } \\
U^{\prime}\end{array}$ \\
\hline$m_{1}$ & 50 & 2 & 25 & 0.0147 & -0.0015 & 0.0020 & & \\
\hline$m_{2}$ & 50 & 2 & 25 & 0.0179 & 0.0018 & 0.0025 & 0.0158 & 0.0316 \\
\hline$v_{1}$ & 0.56 & 2 & 0.28 & 0.0227 & 0.8387 & 0.0131 & & \\
\hline$v_{2}$ & 0.40 & 2 & 0.20 & 0.0227 & 0.7464 & 0.0083 & & \\
\hline
\end{tabular}

Table 3 Uncertainties of speed pre-crash of vehicle $B$

\begin{tabular}{|c|c|c|c|c|c|c|c|c|}
\hline $\begin{array}{l}\text { Input } \\
\text { parameters } \\
x_{i}\end{array}$ & $\begin{array}{l}\text { Changes } \\
\text { radius } \\
a_{i}\end{array}$ & $\begin{array}{l}\text { Contains } \\
\text { factor } \\
k\end{array}$ & $\begin{array}{l}\text { Standard } \\
\text { Uncertainty } \\
u_{\mathrm{xi}}\end{array}$ & $\begin{array}{l}\text { Relative } \\
\text { standard } \\
\text { uncertainty } \\
u_{x i}^{\prime}\end{array}$ & $\begin{array}{l}\text { Uncertainty } \\
\text { propagation } \\
\text { coefficient } \\
\delta_{i}\end{array}$ & $\begin{array}{l}\text { Relative standard } \\
\text { uncertainty } \\
\text { component } \\
u_{v_{\text {ta }}^{\prime}}^{\prime}\end{array}$ & $\begin{array}{l}\text { Relative combined } \\
\text { standard } \\
\text { uncertainty } \\
u_{v 10}^{\prime}\end{array}$ & $\begin{array}{l}\text { Expanded } \\
\text { uncertainty } \\
U^{\prime}\end{array}$ \\
\hline$m_{1}$ & 50 & 2 & 25 & 0.0147 & 0.0033 & 0.0088 & & \\
\hline$m_{2}$ & 50 & 2 & 25 & 0.0179 & -0.0040 & 0.0107 & 0.0215 & 0.0430 \\
\hline$v_{1}$ & 0.56 & 2 & 0.28 & 0.0228 & 0.4549 & 0.0137 & & \\
\hline$v_{2}$ & 0.40 & 2 & 0.20 & 0.0228 & 0.4226 & 0.0091 & & \\
\hline
\end{tabular}

Table 2 shows the expanded uncertainty of vehicle $A$ is 0.0138 . Thus, the relative expanded uncertainty is 0.0316 . The optimum values for all parameters are substituted into Eq. (2), vehicle $A$ and $B$ 's speed before collision can be obtained. The speed of vehicle A is $18.0 \mathrm{~m} / \mathrm{s}$, and corresponding data of vehicle $B$ is $9.3 \mathrm{~m} / \mathrm{s}$. By uncertainty theory, the speed of the range vehicle $A$ before the collision can be obtained, which is

$v_{10}=18.0 \times(1 \pm 0.0316)=17.4 \sim 18.6 \mathrm{~m} / \mathrm{s}=62.8 \sim 66.8 \mathrm{~km} / \mathrm{h}$.

Similarly, vehicle $B$ 's speed before the collision is $v_{20}=9.3 \times(1 \pm 0.0430)=8.9 \sim 9.7 \mathrm{~m} / \mathrm{s}=32.0 \sim 34.9 \mathrm{~km} / \mathrm{h}$.

\section{Video speed method validation}

The road accidents have monitoring equipment, which can be used to calculate the vehicle speed (Wong et al., 2014). As shown in Fig. 5, when the accident two vehicles into the monitor screen, they happen a complete vertical side collision.
After analysis of surveillance video, the video picture rate is 25 frames per second. Vehicle feature point speed method can be used in this case. In accordance with the time to analyze the relationship between the distance, travel speed of the two vehicles before the collision can be calculated. Vehicle $A$ 's left front wheel center and rear center were set as reference point. The left side of the front point and rear point of vehicle $B$ was finally fixed as reference point. Reference point and the relevant data are shown in Table 4.

Surveillance video recorded the exact course of the accident. Thus, to meet the video quality and camera angles, the video picture obtained speed value can more accurately reflect the facts. Therefore, the speed obtained by the video can be used to verify the uncertainty speed. As can be seen, the speed results obtained by the two methods in a similar range to confirm each other. 


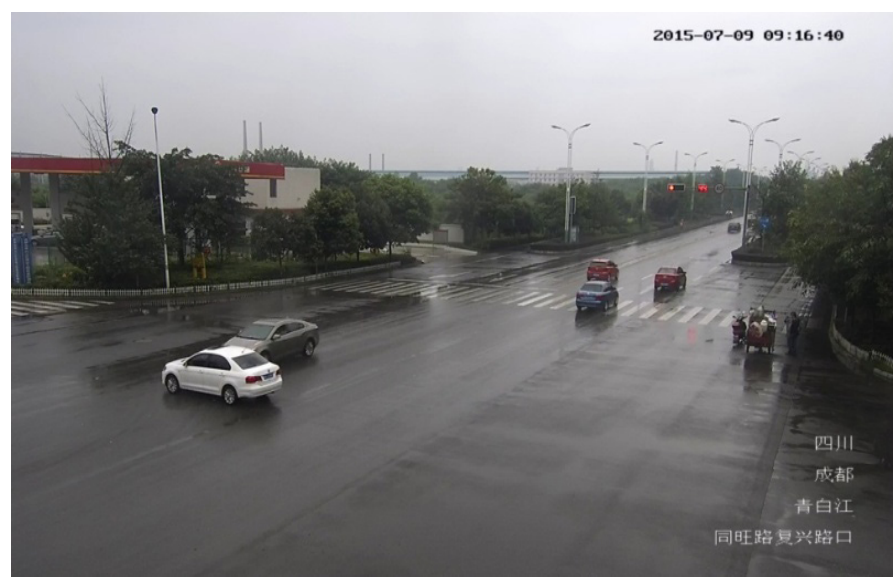

Fig. 5 Video picture

Table 4 Video speed computing

\begin{tabular}{lllll}
\hline & Reference point & $\begin{array}{l}\text { Time (Number } \\
\text { of frame) }\end{array}$ & $\begin{array}{l}\text { Distance } \\
(\mathrm{m})\end{array}$ & $\begin{array}{l}\text { Speed } \\
(\mathrm{km} / \mathrm{h})\end{array}$ \\
\hline Vehicle $A$ & wheel center & 4 & 2.857 & 64.3 \\
Vehicle $B$ & front /rear point & $12-13$ & 4.487 & $31.1-33.7$ \\
\hline
\end{tabular}

\section{Conclusions}

Determining the speed of the vehicle in traffic accident is the key. Since the site inspection and technical level and other restrictions, there is always uncertainty parameter. Through the analysis of traffic accidents related parameters, some parameters were selected as uncertain factors. According to the theory of uncertainty, the vehicle speed in the collisions was performed based on the uncertain factors. Through the analysis of a case of traffic accident using uncertainty theory and video picture, which shows that the speed results obtained by the two methods in a similar range to confirm each other. Thus, the method to calculate the speed of uncertainty can be extended in practice.

\section{Acknowledgement}

The project presented in this article is supported by China National Institute of Standardization (Vehicle Safety Analysis Based on In-depth Research on Vehicle Accidents, 15203266) and Sichuan Key Laboratory of Vehicle Measurement, Control and Safety (Pedestrian and vehicle collision accident reconstruction uncertainty analysis model, SZJJ2015-044).

\section{References}

Adrian, B. E., Stephen, P. G. (2015). Speeding in urban environments: are the time savings worth the risk. Accident Analysis \& Prevention. 85, pp. 239-247. https://doi.org/10.1016/j.aap.2015.09.018

Bartlett, W., Wright, W., Masory, O., Brach, R., Baxter, A., Schmidt, B., Navin, F., Stanard, T. (2002). Evaluating the uncertianty in various measurement tasks common to accident reconstruction. SAE Technical Paper. pp. 57-70. https://doi.org/10.4271/2002-01-054

Cao, Y., Zuo, Z., Xu, H. (2014). Analysis of traffic conflict characteristic at temporary reversible lane. Periodica Polytechnica Transportation Engineering. 42(1), pp.73-76.

https://doi.org/10.3311/PPtr.7068
Çavdar, A., Uçar, M., Kiliçaslan, I. (2008). Checking of the high speed faults caused to traffic accident and controling by active safety systems. Journal of the Faculty of Engineering and Architecture of Gazi University. 23(1), pp.187-198 (in Turkish)

Çelik, S., Senger, O. (2014). Risk factors affecting fatal versus non-fatal road traffic accidents: the case of Kars province, Turkey. International Journal for Traffic and Transport Engineering. 4(3), pp. 339-351. https://doi.org/10.7708/ijtte.2014.4(3).07

Cheng, G., Pei, Y. (2008). Relationship between speed and traffic accident and speed limit on freeway. Journal of Harbin Institute of Technology (New Series). 15(2), pp. 149-154 (in Chinese)

Cui, K., Xia, H., Xia, C, Wu, X. (2014). Equivalent static force calculation methods for transient impact force of a vehicle in collision with piers. Journal of Vibration and Shock (in Chinese). 33(4), pp. 48-53. https://doi.org/10.13465/j.cnki.jvs.2014.04.010

Fonda, A. (2004). The effects of measurement uncertainty on the reconstruction of various vehicular collisions. SAE Technical Paper. https://doi.org/10.4271/2004-01-1220

Helton, J. C., Davis, F. J. (2003). Latin hypercube sampling and the propagation of uncertainty in analyses of complex systems. Reliability Engineering and System Safety. 81(1), pp. 23-69. https://doi.org/10.1016/S0951-8320(03)00058-9

Peer, E. (2011). The time-saving bias, speed choices and driving behavior. Transportation Research Part F: Traffic Psychology and Behaviour. 14(6), pp. 543-554. https://doi.org/10.1016/j.trf.2011.06.004

Qu, W., Ge, Y., Xiong, Y., Carciofo, R., Zhao, W., Zhang, K. (2015). The relationship between mind wandering and dangerous driving behavior among Chinese drivers. Safety Science. 78, pp. 41-48. https://doi.org/10.1016/j.ssci.2015.04.016

Shen, R., Ai, J., Pei, Y. (2009) Uncertainty analysis of collision velocity in motor vehicle crashes using an evidential reasoning algorithm. In: ICCTP 2009: Critical Issues In Transportation Systems Planning, Development, and Management. pp. 906-913.

https://doi.org/10.1061/41064(358)127

Taylor, M.C., Baruya, A., Kennedy, J. V. (2002). The relationship between speed and accidents on rural single-carriageway roads. Transport Research Laboratory. Crowthorne, Berkshire.

Tarko, A. P. (2009). Modeling drivers' speed selection as a trade-off behavior. Accident Analysis \& Prevention. 41(3), pp. 608-616. https://doi.org/10.1016/j.aap.2009.02.008

Taylor, M. C., Lynam, D. A., Baruya, A. (2000). The effects of drivers' speed on the frequency of road accidents. Transport Research Laboratory. Crowthorne, Berkshire.

Ward, J., Agamennoni, G.,Worrall, S., Nebot, E. (2014). Vehicle collision probability calculation for general traffic scenarios under uncertainty. Intelligent Vehicles Symposium Proceedings. In: 2014 IEEE Intelligent Vehicles Symposium Proceedings, Dearborn, MI, 2014, pp. 986-992. https://doi.org/10.1109/IVS.2014.6856430

Wojciech, W., Jan, U. (2006). Determination of vehicle velocities and collision location by means of Monte Carlo simulation method. SAE Paper No. 2006-01-0907. https://doi.org/10.4271/2006-01-0907

Wojciech, W., Jan, U. (2007). Uncertainty of calculation results in vehicle collision analysis. Forensic Science International. 167, pp. 181-188. https://doi.org/0.1016/j.forsciint.2006.06.061

Wong, T., Tao, C., Cheng, Y., Wong, K., Tam, C. (2014). Application of crossratio in traffic accident reconstruction. Forensic Science International. 235(2), pp. 19-23.

https://doi.org/10.1016/j.forsciint.2013.11.012 
Yuan, Q., Li, Y., Pei, J. (2001). The uncertain factor method for vehicle-velocity estimate in traffic accident. Journal of Traffic and Transportation Engineering. 1(4), pp. 71-74 (in Chinese)

Zhang, J., Zhang, X., Li, J., Ni, X., Gao, J. (2012). Sensitivity analysis on the selected parameters in typical vehicle collision models. Automotive Engineering. 34(10), pp. 905-908. (in Chinese)

Zhao, Y., Zhang, J., He, X. (2015). Risk factors contributing to taxi involved crashes: a case study in Xi'an, China. Periodica Polytechnica Transportation Engineering. 43(4), pp. 189-198.

https://doi.org/10.3311/PPtr.7742 